\title{
CAN FRACTURE MECHANICS PREDICT DAMAGE DUE DISASTER OF STRUCTURES?
}

\author{
Nagesh H.E', G. Appa Rao \\ ${ }^{1}$ PhD Scholar, Structural Division, Department of Civil Engineering, Indian Institute of Technology Madras, Chennai- \\ 600036, India \\ ${ }^{2}$ Professor, Structural Division, Department of Civil Engineering, Indian Institute of Technology Madras, Chennai- \\ 600036, India
}

\begin{abstract}
This paper discusses shortcomings of existing code provisions for design of reinforced concrete structures, and need for application of fracture mechanics in design of such structures. For a structure to perform satisfactorily in case of disastrous incidents, care must be exercised at the time of design of structure itself. Fracture mechanics approach for design of structures ensures rational design maintaining safety with reasonable safety margin. Currently, several national and international codes of practice do not recognize the size effect on strength and serviceability of structures. In the design of structures with concrete, the size effect needs to be incorporated to avoid sudden failures. Generally laboratory based tests have limitation on size of members, which are relatively very small compared to actual large structures whose strength cannot be extrapolated. The incorporation of effect of size and other fracture parameters can yield improvement in the design of members with better prediction of safety margin.
\end{abstract}

Keywords: Fracture mechanics, Size effect, Minimum reinforcement, Ductility, Shear strength. $* * *$

\section{HOW SIGNIFICANT SIZE EFFECT IN} CONCRETE STRUCTURES?

According to the strength of materials approach, large size and small size beams fail at same stress levels, if the given material properties. But in practical the large size beams fail at lower stress levels than small size beams. In designer point of view, the most common examples for size effect are, in bending test of concrete beam the strength decreases with increase in beam depth. Shear strength of geometrically similar concrete beams also found to be decreasing as the size increases. Size effect in shear is more predominant than in flexure. Overall it is noticed from experiments that as the size increases there will be transition from ductile to brittle failure, if all other properties maintained same. This change in material properties with volume is known as size effect.

The main causes for size effect is (i) Statistical due to material strength randomness, according to Weibull statistical theory i.e. as the size increases, volume also increases along with percentage of voids also increases resulting in strength reduction because of material heterogeneity. (ii) Energetic due to energy release which causes stress redistribution, when a large crack or a large fracture process zone (FPZ) containing damaged material develops before the maximum load is reached and discontinuities in flow of stress in case of cracks.

Quasibrittle materials like concrete exhibit two types size effects that can be studied according to cohesive fracture mechanics or (NLEFM), The size effect in failures occurring (i) at macro-crack initiation, which is typical of plain concrete. (ii) After large stable crack growth, which is typical in reinforced concrete, especially shear in beams. The latter is due to energy release associated with stress redistribution caused by a large crack.

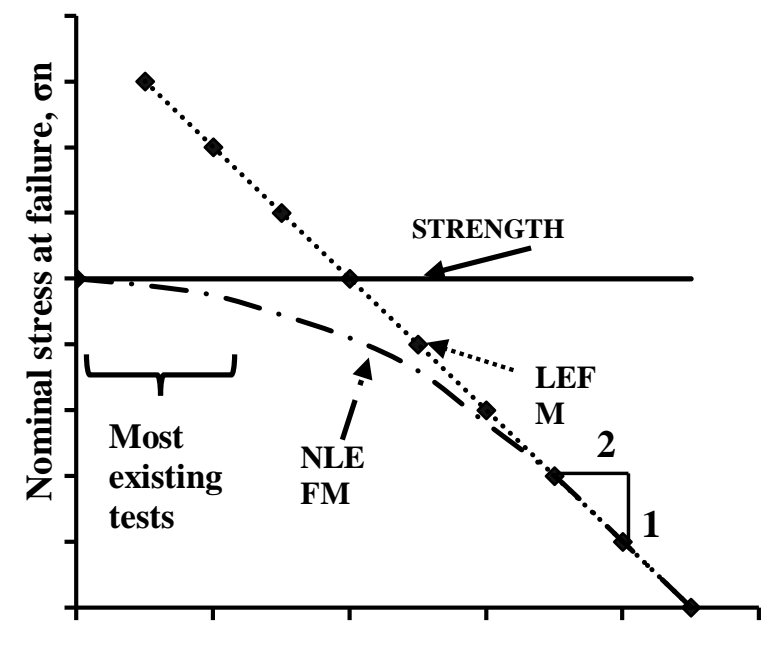

Log (Size)

Fig 1 Size Effect according to strength criteria, linear and nonlinear fracture mechanics

According to strength theory, the failure criterion is expressed in terms of stresses or strains which is calculated according to theories of elasticity and plasticity. The failure condition is indicated by the condition $\sigma_{\mathrm{n}}=\mathrm{f}_{\mathrm{t}}$, where $\mathrm{f}_{\mathrm{t}}$ is the direct tensile strength of concrete. $\sigma_{\mathrm{n}}$ is the nominal stress at 
failure characterizing the stress state at a certain critical point in structure. For dimensionality purpose, $\sigma_{n}=c_{n} \times$ $(P / b d)$ where, $\mathrm{c}_{\mathrm{n}}$ is the coefficient which is independent of the size, shape and loading. $P$ is the load, $d$ is the characteristic dimension and $\mathrm{b}$ is the thickness. The above relationship between $\log \left(\sigma_{\mathrm{n}}\right)$ vs. $\log$ (size) which is a nondimensional size parameter $\log \left(\mathrm{d} / \mathrm{d}_{\mathrm{a}}\right)$, where ' $\mathrm{d}$ ' is the characteristic dimension and ' $\mathrm{d}_{\mathrm{a}}$ ' is the maximum size of the aggregate. It can be seen from Fig 1, according to the strength criteria it is horizontal line, which is independent of the size of member. In Linear Elastic Fracture Mechanics (LEFM) failure criterion is expressed in terms of the energy consumed per unit crack length increment and $\sigma_{\mathrm{n}}$ varies inversely as $\sqrt{ }$ d. so the variation of $\log \left(\sigma_{n}\right)$ vs. $\log$ (size) is a straight line with a slope of $-1 / 2$ as shown in Fig. 1. The true size effect in concrete structures can be represented as a gradual transition from the horizontal line to the inclined straight line according to Non Linear Elastic Fracture Mechanics (NLEFM).

\section{PRESENT DESIGN BASIS}

Presently all national and international codes of practice are based on tests conducted on small size specimens at various laboratories. The codes do not explain or limitations of its application up to certain size and the same formulae are being used to design large structures also without knowing its limitations. The extrapolation should be well anchored in a theory so that the practical results match well with the extrapolated values.

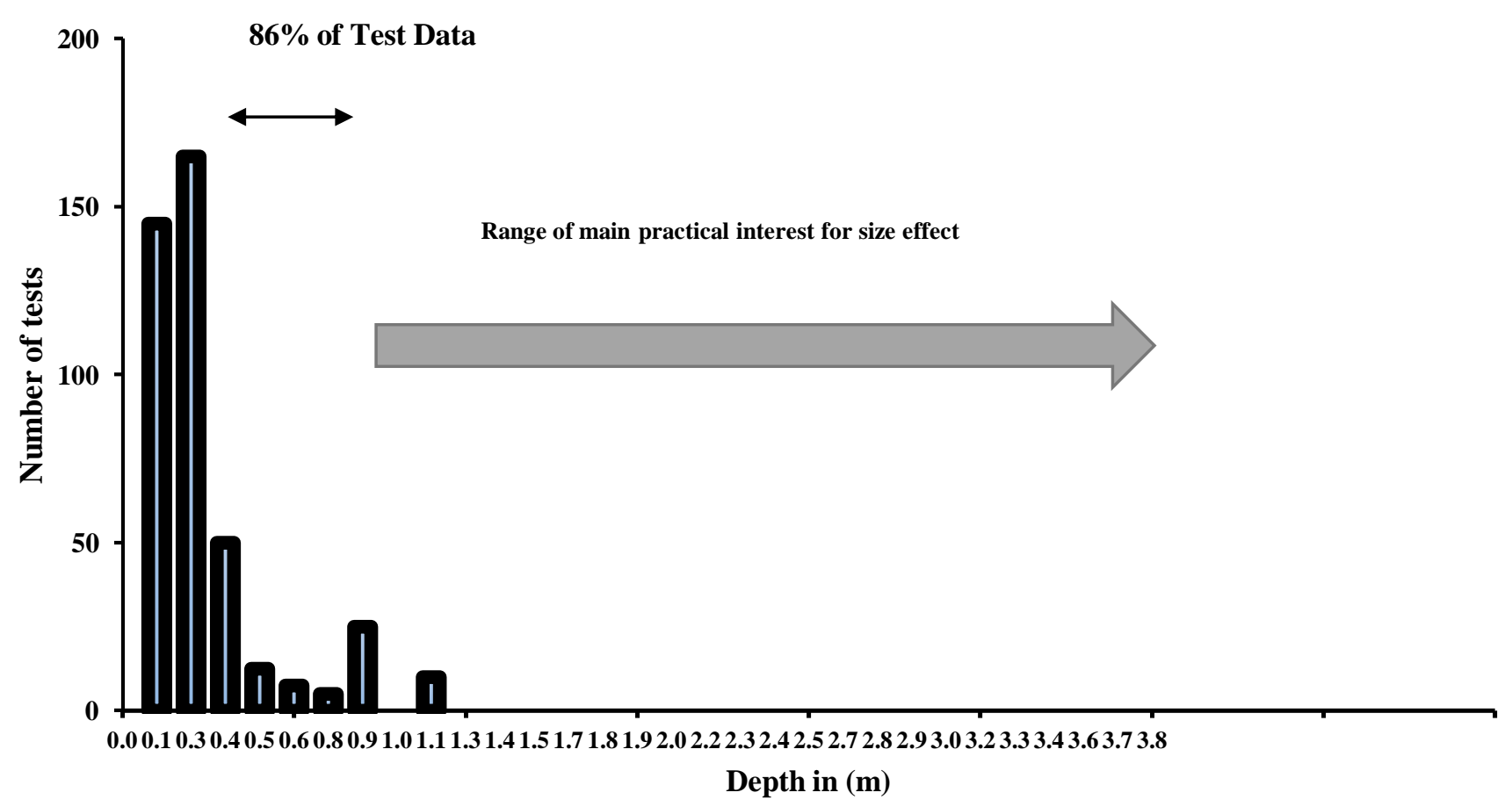

Fig 2 Histogram of beam depth (number of test data vs. depth) Courtesy: Bazant and Yu (2005)

Figure 2 shows the histogram of the number of test data versus beam depth, 'd' according to the database compiled by subcommittee $445 \mathrm{~F}$ of the American Concrete Institute (ACI). The size effect is of practical concern mainly for beam depths ranging from $1.0 \mathrm{~m}$ to $15.0 \mathrm{~m}$. Unfortunately, $86 \%$ of all the available test data pertain to beam depths less than $0.5 \mathrm{~m}$. This highlights the importance of testing larger size test specimens in laboratories rather than smaller size. The extrapolation should be anchored to a theory in order to ensure safe designs.

\section{RESEARCH SIGNIFICANCE}

Present design codes mainly based on strength and serviceability aspects. Neglecting tensile strength of concrete results in conservative designs. Failure of RC beams according to the conventional strength or yield criterion exhibit no size dependence, nor should the size of the beam have any effect on its ductility. The effect of size of member and ductility in the design of RC members can be predicted by using fracture mechanics. The fracture mechanics based research also shows that, there is a need to test large size specimens in laboratories.

\section{BACKGROUND}

The first attempt recorded on use of fracture mechanics of concrete was by Kaplan (1961) attempting the use of linear elastic fracture mechanics (LEFM). It was confirmed that the large size beams exhibit strong size effect on nominal stress at failure, which is size independent on small beams (Walsh, 1972). The first theoretical model for reinforced concrete beam in flexure was by Carpinteri (1981, and 1984) adopted the principles of fracture mechanics to solve the problem of a reinforced concrete beam with an initial edge crack ' $a$ ' subjected to bending. According to this 
elementary model, moment and steel forces applied remotely from the crack faces are superposed. The assumption was that concrete behaves as a linear elastic material and steel as a linear elastic-perfectly plastic. After that many modifications and refined models are now available. Bazant in his series of works showed the significance of size effect in designing civil engineering structures. Bazant demonstrated in theoretical model that size effect mainly caused by stress redistribution and localization of cracking damage associated with the release of energy stored in the structure. Many theoretical models and applications of size effect also contributed by Bazant. It includes crack band model (1983), Bazant size effect law (1984) and nonlocal softening damage models.

\section{SIZE EFFECT ON DUCTILITY}

The performance of structures due to loading effects of earthquake, storms and other natural disasters mainly depends on ductility of the members. Because ductility ensures ductile failure which prevents sudden or brittle failure that leads to sudden collapse. The following are some of the investigations related to ductility and size effects in beams.

Hillerborg (1990) made theoretical investigation of rotational capacity of $\mathrm{RC}$ beams by applying fracture mechanics concepts. It has been concluded that the rotational capacity is nearly inversely proportional to the depth of beam. Bigaj and Walraven (1993) investigated size effect on rotational capacity of beams. They reported that the members with small dimensions show much higher plastic rotations than members with larger dimensions of same characteristics. Carpinteri et al. (2009) developed new model for the analysis of size-scale effects on the ductility of RC beams in bending. They concluded that behavior tends to become more brittle as beam depth increases. This behavior is very well evidenced by a progressive reduction of the beam rotation at failure.
Rao et al. (2008) derived ductility number from principles of dimensional analysis, which is function of size of beam (h), fracture energy $\left(G_{F}\right)$, yield strength of steel $\left(f_{y}\right)$, modulus of elasticity of concrete $\left(\mathrm{E}_{\mathrm{c}}\right)$, area of steel reinforcement $\left(\mathrm{A}_{\mathrm{s}}\right)$ and gross-area of cross-section (A) $N_{D}=\frac{A_{s t} f_{y}}{b h} \frac{\sqrt{h}}{\sqrt{G_{F} E_{c}}}$. They concluded that the ultimate flexural strength and ductility of RC beam decreases with increase in size. The ductility factor increases with increase in size for certain limit and again it decreases. Carpinteri et al. (2013) outlined conditions for the structural design of RC elements exhibiting ductile response. The decrease in one parameter among depth $(\mathrm{h})$, steel ratio $(\rho)$, and yield $\operatorname{stress}\left(\sigma_{y}\right)$, or the increase in concrete tensile properties $\left(\sigma_{u}\right)$ or fracture energy $\left(\mathrm{G}_{\mathrm{F}}\right)$, all the other parameters being kept constant, determines a transition from ductile response to unstable tensile crack propagation. On the other hand, the increase in $\mathrm{h}, \rho$, and $\sigma_{y}$, or the decrease in ultimate compressive stress $\left(\sigma_{c}\right)$ or $\left(\mathrm{G}_{\mathrm{c}}\right)$ all other parameters being kept constant, produces a transition towards crushing failure without steel yielding. In an overview it is noticed that as size increases brittleness of the structure also increases. Hence this phenomenon should be accounted while designing any structures. Underestimation of ductility in large scale specimens leads to transition from ductile to brittle behavior, which is not desirable and it has to be accounted in codes.

Figure 3. shows the plot of plastic rotation $\left(\varphi_{\mathrm{PL}}\right)$ versus relative neutral axis position $(\mathrm{x} / \mathrm{d})$ with comparison of Eurocode 2 provision and numerical results of Carpinteri and Corrado (2010). From the observation of plot it is clear that, Eurocode 2 underestimates the plastic rotational capacity of small size beam $(0.2 \mathrm{~m}$ depth $)$ and overestimates the rotational capacity of large size beam $(0.6 \mathrm{~m}$ and $0.8 \mathrm{~m}$ depth).

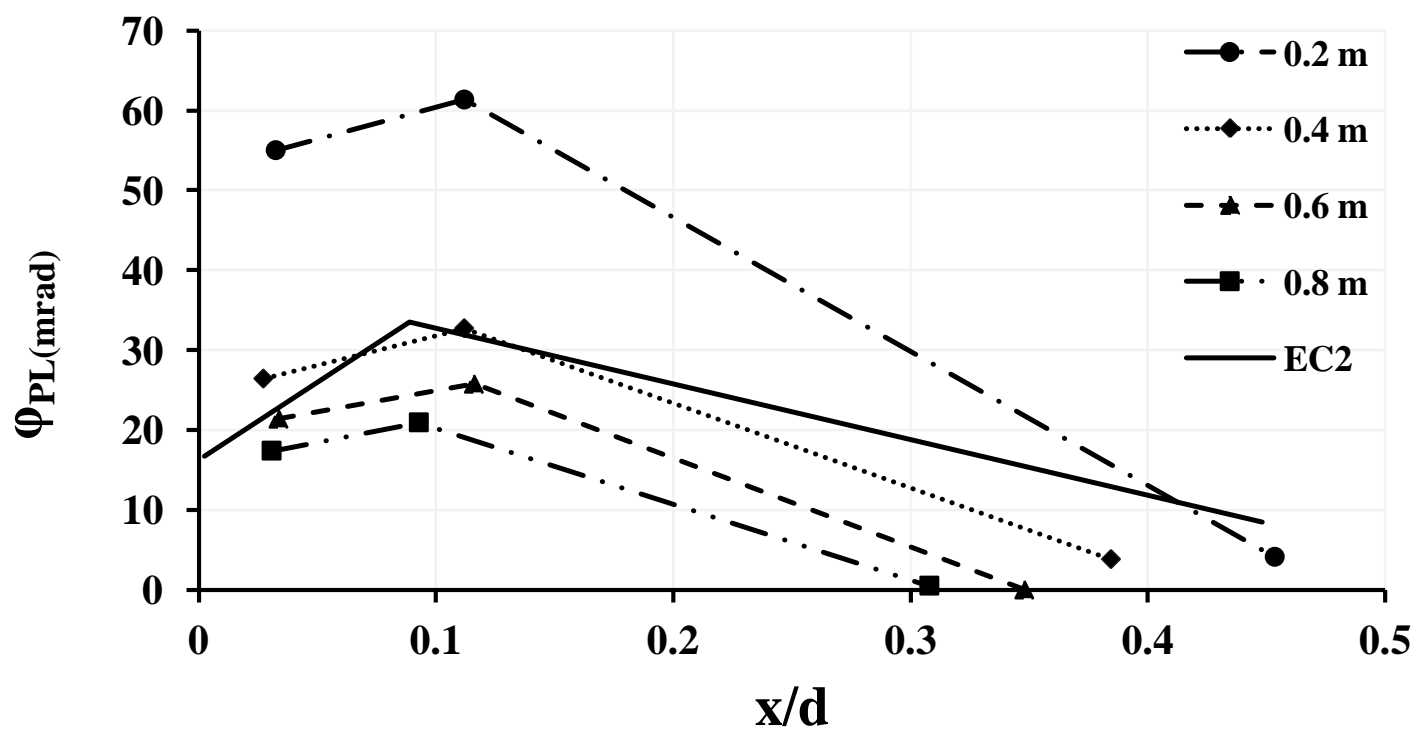

Fig 3 Plastic rotation vs. relative neutral axis 


\section{FRACTURE MECHANICS APPLICATIONS IN DESIGN}

Safe design of structure requires a valid mechanical model and probabilistic analysis. Fracture mechanics provides a scientific approach to define the failure of concrete. The application of fracture mechanics to the design practice is possible through the size effect. The two main applications are presented here.

\subsection{Minimum Reinforcement}

Problems that can be solved using principles of fracture mechanics is the provision of minimum reinforcement because lightly reinforced beams are fracture sensitive. Currently, various national and international codes of practice provide empirical formulae for evaluation of minimum reinforcement. Even though they are not rational but performed satisfactorily for many years in design. These codes disregard the nonlinear contribution of concrete in tension and the size effects. They normally incorporated compressive strength of concrete and yield strength of steel as main parameters in the empirical formulae. Provisions in American Concrete Institute (ACI) and Australian Standards (AS) codes consider the compressive strength of concrete, but British Standards (BS) and Indian Standards (IS) codes do not. Australian Standards (AS) and Norway Standards (NS) code defines minimum flexural reinforcement as a function of size of member where as other codes do not.

Conventional method of evaluating cracking moment using modulus of rupture (which is not strictly a material property) for evaluating minimum reinforcement is empirical in nature. The behavior of concrete in tension, crack initiation, and crack propagation and fracture process zone are well described in current fracture mechanics of concrete approach. Such provisions ensure sufficient ductility in flexural members by providing a reasonable margin of safety between the first cracking and ultimate flexural loads. The use of fracture mechanics of concrete enables rational procedure to evaluate the optimum steel reinforcement which ensures safe designs incorporating the size effect, and other influencing parameters.

\subsection{Evaluation of Shear Strength in Deep Beams}

It is observed from experimental results of Kani (1967) that about $40 \%$ of the ultimate shear strength reduction was observed when the beam depth was increased from $300 \mathrm{~mm}$ to $1200 \mathrm{~mm}$ in deep beams without stirrups. Rao and Sundaresan (2012) proposed equation for predicting shear strength in deep beams incorporating size (depth) of the beam and other influencing parameters. Bazant and $Y u$ (2009) showed that an increase of beam depth from $0.3 \mathrm{~m}$ to $1 \mathrm{~m}$ raises the shear failure probability of beams without stirrups from $\left(10^{-6}\right)$ to $\left(10^{-3}\right)$ per lifetime. Yu and Bazant (2011) demonstrated from experimental database and from numerical studies that size effect on shear strength cannot be suppressed by the presence of minimum or heavier stirrups. For beams less than $1 \mathrm{~m}$, stirrups can mitigate significantly but not in case of beams more than $1 \mathrm{~m}$. The current standard
ACI 318-2008 and other codes specifies for RC beams with shear reinforcement, whether minimum or heavier, a size independent shear strength equation. Hence these code provisions need to be verified and adjusted to size dependent shear strength.

Other applications such as brittle failures of concrete structures (shear and torsion of R.C. beams with or without stirrups, plain concrete flexure, slab punching, column failure, bar embedment length, splices, bearing strength, etc.) can also be studied by using fracture mechanics principles.

\section{CASE STUDIES}

\subsection{Failure of Tricell of Sleipner Oil Platform}

This case study is about the failure of Sleipner an Oil Platform, Norway in 1991. The tricell is $190 \mathrm{~m}$ tall, structure imploded under water head of $67 \mathrm{~m}$, causing the platform to sink. Investigation team outlines factors caused failure. (i) The wall failed as a result of a combination of poor finite element mesh (ii) insufficient anchorage of the reinforcement in a critical zone. A separate investigation documented a third contributing factor, the size effect in the shear failure shown in figure. 4. which reduced the shear capacity by about $40 \%$. Caissons and shear failure of tricell are shown in the figure. 4 . 


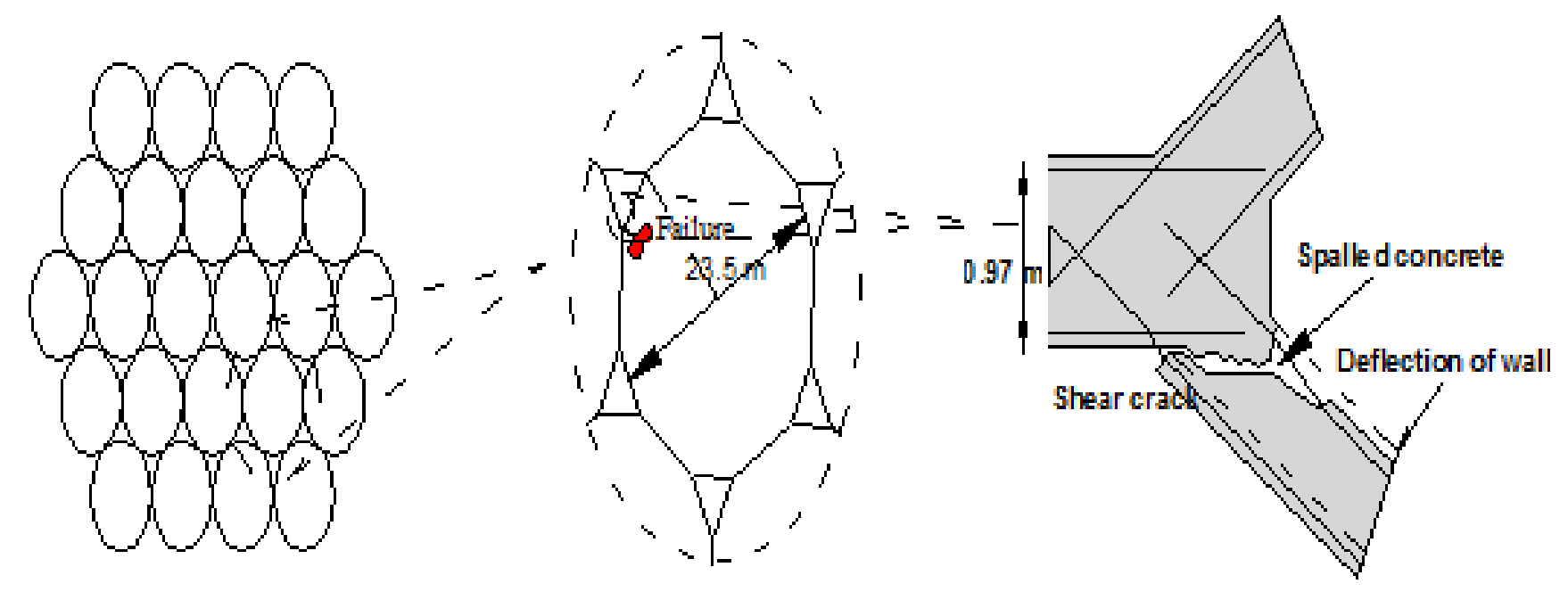

Fig 4 Sleipner oil platform caisson cells and failure of tricell

\subsection{Failure of Koror-Babeldaob (KB) Bridge}

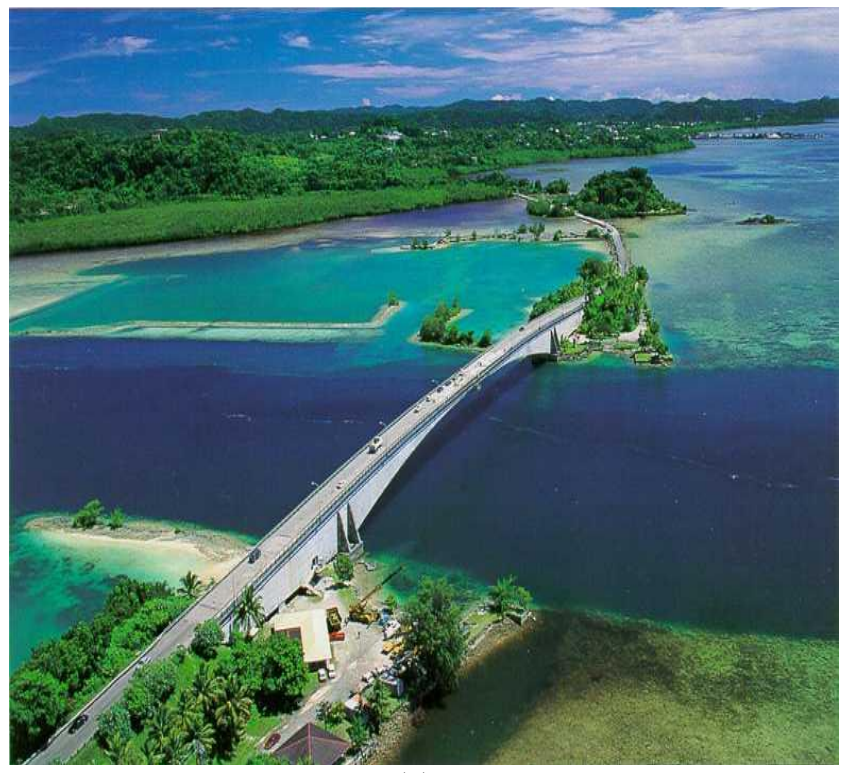

(a)

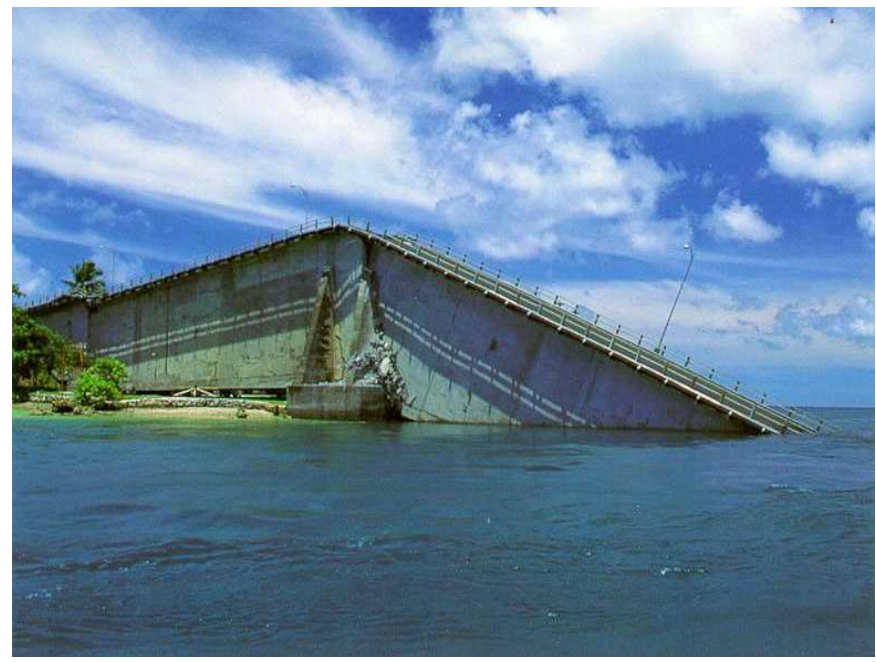

(b)

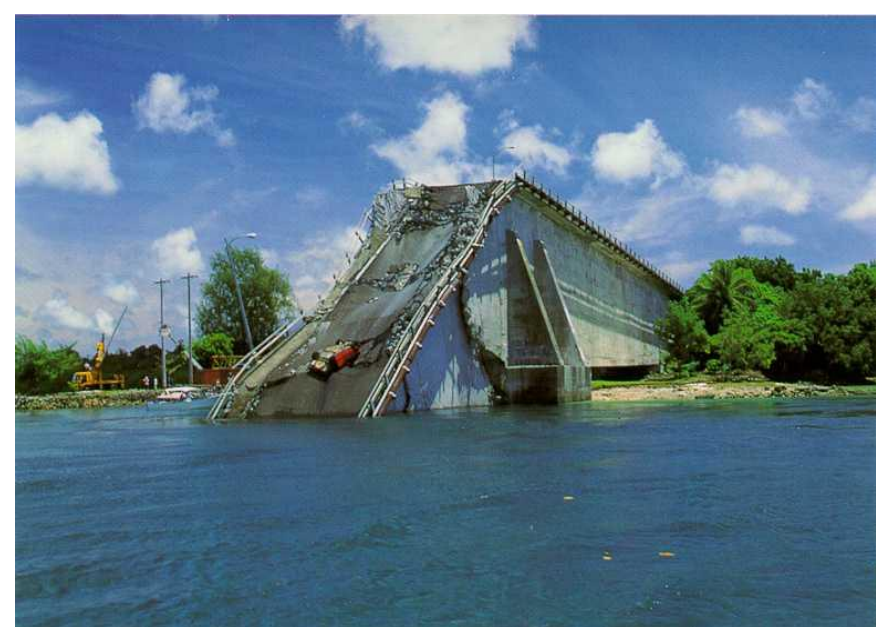

(c)

Fig 5 Koror-Babeldaob (KB) Bridge (a) Before collapse (b) and (c) After collapse 
Koror-Babeldaob (KB) bridge was built in 1977 in the Republic of Palau. Collapse of bridge was occurred in $26^{\text {th }}$ September 1996 and investigation showed that erroneous prediction of deflection due to creep and shrinkage, and inappropriate remedial prestressing was major cause for collapse. Consideration of size effect due to brittleness of concrete would have prevented the collapse of above bridge. The low safety margin and severity of size effect on large size members causes catastrophic collapse. Size effect factor for normal strength concrete can have a maximum value of 2.0, the size effect alone would be sufficient to cause the collapse even though a safety margin related to error in the design formulae and material randomness are included.

It is also remarkable to note that size effect must have contributed to other disasters (e.g. bridges in Northridge. Loma Prieta and Kobe earthquakes. Schoharie Bridge, Shelby AF Warehouse, St. Francis Dam).

\section{CONCLUSION}

Fracture mechanics based designs give a promising safe design of reinforced concrete structures incorporating size effect and fracture properties of concrete. In real structures like bridges, size of members is relatively large, so brittleness also is high. If this behavior is properly accounted for in the design, probability of failure in case of any natural disaster can be avoided. This reveals that introduction of size effect in the specifications of concrete design codes is of the utmost practical importance.

\section{REFERENCES}

[1] Bazant, Z.P. (1983) "Crack band theory for fracture of concrete" Materials and structures, 16, 155-177.

[2] Bazant, Z.P. (1984) "Size effect in blunt fracture: concrete, rock, metal" Journal of Engineering Mechanics, ASCE. 518-535.

[3] Bazant, Z.P., and Yu, Q. (2004) "Size effect in concrete specimens and structures: New problems and progress" Fracture Mechanics of Concrete Structures-5 (Proc., FraMCoS-5 Vail, Colo.), Vol. 1, 153-162.

[4] Bazant, Z.P., and Yu, Q (2005) "Designing against size effect on shear strength of reinforced concrete beams without stirrups: I. formulation" ASCE, Journal of structural engineering. (131)1877-1885.

[5] Bazant, Z. P., Planas, J. (1998) "Fracture and size effect in concrete and other quasibrittle materials" CRC Press.

[6] Bazant, Z.P and Pang, S.D (2005) "Effect of size on safety factors and strength of quasibrittle structures: beckoning reform of reliability concepts" The structural engineering convention (sec 2005) Indian institute of science, Bangalore, India.

[7] Yu, Q and Bazant, Z.P (2011) "Can stirrups suppress size effect on shear strength of RC beams?" Journal of structural engineering ASCE, 607-617.

[8] Bosco, C., and Carpinteri, A. (1992) "Fracture mechanics evaluation of minimum reinforcement in concrete structures", in Application of Fracture Mechanics to Reinforced Concrete, Elsevier Applied Science, London, 347-377.
[9] Carpinteri, A., Corrado, M., and Ventura, G. (2013) "Failure mode scaling transitions in $\mathrm{RC}$ beams in flexure: tensile, shearing, and crushing", FraMCoS-8, Spain.

[10] Cadamuro, E., Corrado, M., and Carpinteri, A. (2010) "Size-scale effects on minimum flexural reinforcement in RC beams: application of the cohesive crack model" Fracture Mechanics of Concrete and Concrete Structures - Recent Advances in Fracture Mechanics of Concrete, Seoul.

[11] Carpinteri, A. (1984) "Stability of fracturing process in RC beams", Journal of Structural Engineering. (ASCE), 110, 544-558.

[12] Carpinteri, A. (1999) "Minimum reinforcement in concrete members", ESIS-Technical Committee 9, 1202.

[13] Carpinteri, A., Corrado, M., Mancini, G., and Paggi, M. (2009) "Size-scale effects on plastic rotational capacity of reinforced concrete beams" ACI structural journal, 106, S83.

[14] Carpinteri, A., Corrado, M., Paggi, M., and Mancini, G. (2009) "New model for the analysis of Size-scale effects on the ductility of reinforced concrete Elements in Bending" Journal of engineering mechanics, ASCE, 135, 221-229.

[15] Carpinteri, A. (1981) "A fracture mechanics model for reinforced concrete collapse", IABSE Colloquium on Advanced Mechanics of Reinforced Concrete, Delft, 17-30.

[16] CEB-FIP Model Code 2010, Vol 1, International Federation for Structural Concrete (FIB), Switzerland.

[17] El-Khatieb, W.M.H.M., and Al-Ani, H. (2011) "Steel reinforcement ratio dependency of plastic rotational capacity of reinforced concrete beams" Jordan Journal, 5(4), 480-492.

[18] Hillerborg, A. (1990) "Fracture mechanics concepts applied to moment capacity and rotational capacity of reinforced concrete beams" Engineering Fracture Mechanics, vol.35, No 1/2/3, 233-240.

[19] Kani, G.N.J (1967) "How safe are our large reinforced concrete beams?" ACI J. Proc. 64(3): 128141

[20] Kaplan, M.F. (1961) "Crack Propagation and the fracture of concrete." ACI Journal 58 (11).

[21] Rao, G.A., Aravind, J., and Eligehausen, R. (2007) "Evaluation of minimum flexural reinforcement in RC beams using fictitious crack approach", JoSE, 34(4), 277-283.

[22] Rao, G.A., Vijayanand, I., and Eligehausen, R. (2008) "Studies on ductility and evaluation of minimum flexural reinforcement in RC beams" Materials and Structures, 41, 759-771.

[23] Rao, G.A., and Sundaresan (2012) "Evaluation of size effect on shear strength of reinforced concrete deep beams using refined strut-and-tie model" Sadhana, Vol. 37, Part 1, pp. 89-105.

[24] Walsh, P F. (1972) "Fracture of plain concrete." International Concrete Journal, 46(11), 469-476. 